\title{
HPC2/ELAC2 polymorphisms and prostate cancer risk: analysis by age of onset of disease
}

\author{
JC Meitz', SM Edwards', DF Easton², A Murkin', A Ardern-Jones³, RA Jackson', S Williams', DP Dearnaley ${ }^{1,4}$, \\ MR Stratton', RS Houlston', The Cancer Research UK/BPG UK Familial Prostate Cancer Study \\ Collaborators ${ }^{4}$ and RA Eeles*,1,4
}

\author{
'Institute of Cancer Research, 15 Cotswold Road, Sutton, Surrey SM2 5NG, UK; ${ }^{2}$ Cancer Research UK Genetic Epidemiology Unit, Strangeways Research \\ Laboratory, Worts Causeway, Cambridge CBI 8RN, UK; ${ }^{3}$ Data Management Unit, Translational Cancer Genetics Team, Institute of Cancer Research, \\ 15 Cotswold Road, Sutton, Surrey SM2 5NG, UK (List of collaborators available on request); ${ }^{4}$ Royal Marsden NHS Trust, Downs Road, Sutton, \\ Surrey SM2 5PT, UK
}

The candidate prostate cancer susceptibility gene HPC2/ELAC2 has two common coding polymorphisms: (Ser $\rightarrow$ Leu 217) and $(A l a \rightarrow T h r$ 54I). The Thr54I variant in the HPC2/ELAC2 gene has previously been reported to be at an increased frequency in prostate cancer cases. To evaluate this hypothesis we genotyped 432 prostate cancer patients (including 262 patients diagnosed $\leqslant 55$ years) and 469 UK, population based control individuals with no family history of cancer. We found no significant difference in the frequencies of Thr54I-containing genotypes between cases and controls $(\mathrm{OR}=1.4 \mathrm{I}, 95 \% \mathrm{Cl} 0.79$ 2.50). The association remained non-significant when the analysis was restricted to cases divided by age of onset into those diagnosed $\leqslant 55$ years $(\mathrm{OR}=1.50,95 \% \mathrm{Cl} 0.79-2.85)$ or to patients diagnosed $>55$ years $(\mathrm{OR}=1.27,95 \% \mathrm{Cl} 0.59-2.74)$. We conclude that any association between the Thr54I variant and prostate cancer is likely to be weak. British Journal of Cancer (2002) 87, 905 -908. doi: I 0.I038/sj.bjc.6600564 www.bjcancer.com

(c) 2002 Cancer Research UK

Keywords: ELAC2; HPC2; prostate cancer ( $\mathrm{PrCa}$ ) susceptibility; polymorphisms

The HPC2/ELAC2 gene, located on chromosome 17p11.2 was recently mapped and characterised (Tavtigian et al, 2001). The ELAC2 gene product has an amino acid sequence similarity to DNA interstrand crosslink repair proteins (PSO2, SNM1) and the $73-\mathrm{kD}$ subunit of mRNA $3^{\prime}$ end cleavage and polyadenylation specificity factor (CPSF73). Tavtigian et al (2001) reported linkage to prostate cancer ( $\mathrm{PrCa}$ ) in this region, using a set of 33 extended multiple case pedigrees from Utah. They obtained a maximum two point lod score of 4.5 at marker D17S1289 $(\theta=0.07)$ and a three point lod score of 4.3 using the markers D17S1289 and D17S921 $(\theta=0.10)$ using a recessive model. Mutational analysis of HPC2/ ELAC2, using an extended PrCa family set of 127 pedigrees with individual family lod scores of $\geqslant 1$ or $>$ six cases sharing a haplotype, revealed that a subset of individuals in one family carried a germline frameshift mutation (164linsG). A common missense variant (serine to leucine at amino acid 217) was found in $13 \%$ of PrCa cases $v s 9 \%$ of unaffected pedigree members and $6 \%$ of controls (Tavtigian et al, 2001). The authors also reported a second non conservative missense change in the ELAC2 gene, alanine to threonine at amino acid 541, that lies at the amino border of the histidine motif in the ELAC2 gene (Tavtigian et al, 2001). These two polymorphisms are in strong linkage disequilibrium, such that the Thr541 allele only occurs on a Leu217 background. The authors obtained a higher frequency of Thr541 carriers in PrCa cases in their families than in 'divergent controls' (unaffected spouses from other cancer families) $(\mathrm{OR}=3.1, P=0.022)$, though not when compared with unaffected individuals in the PrCa families. Tavtigian et al (2001) postulate that the Leu217/Thr541

*Correspondence: RA Eeles; E-mail: ros@icr.ac.uk

Received II March 2002; revised I5 July 2002; accepted 8 August 2002 haplotype results in more functional disruption of the protein than the commoner Leu217/Ala541 haplotype. An association between the Thr541 allele and PrCa was also reported by Rebbeck et al (2000), who estimated an odds ratio for PrCa of 2.37 (95\% CI $1.06-5.29)$ associated with carrying the Thr541 allele. Among the 266 male control subjects (matched for age and race), a Thr541 allele frequency of $2.9 \%$ and a Leu217 allele frequency of $31.6 \%$ were reported. Suarez et al (2001) also found a significantly higher frequency of Thr541 alleles in PrCa cases than in controls (OR=3.6, $95 \%$ CI $1.8-7.3$ ) in a study of 257 multiplex PrCa sibships and 355 controls. However, four recently published studies (Rökman et al, 2001; Vesprini et al, 2001; Wang et al, 2001; Xu et al, 2001) reported no evidence for an association between the Leu217 and Thr541 variants and PrCa risk. Xu et al (2001) also reported no linkage at HPC2 after genotyping 159 hereditary PrCa families (with at least three affected family members) and analysing them using both parametric and nonparametric methods.

In an attempt to confirm or refute the association of HPC2 and $\mathrm{PrCa}$, and in addition to investigate any association with age of onset, we have genotyped these variants in a series of $432 \mathrm{PrCa}$ patients from the UK, including 262 patients diagnosed $\leqslant 55$ years, and 469 controls.

\section{MATERIALS AND METHODS}

\section{PrCa patients}

This study was conducted on prostate cancer samples from patients treated in the UK. We obtained 432 blood samples from two series of PrCa Patients via consultants collaborating in the Cancer Research UK (formerly Cancer Research Campaign)/British Prostate Group (CRC/BPG) UK Prostate Familial Cancer Study 
(described by Eeles, 1999) and from the Royal Marsden NHS Trust (RMNHST) PrCa clinic. The PrCa cases were collected in two sets.

Series (I) A national study of early onset $\mathrm{PrCa}$, selecting patients diagnosed at age $\leqslant 55$ years; patients were referred into this study through collaborating clinicians across the UK (The CRC/BPG Study). Patients were not selected on the basis of their family history. The average age of diagnosis of the PrCa patients was 51 years (range $24-55$ years).

Series (II) A systematic series of PrCa cases, ascertained through the Urology Unit of the Royal Marsden Hospital, London, UK over the period 1992-1993. These patients were unselected for age or family history. The average age of diagnosis of the PrCa patients was 69 years (range 55-80 years).

In the analysis patients were subdivided into those diagnosed $\leqslant 55$ years $(n=262)$ and those diagnosed $>55$ years $(n=170)$. For the purpose of this analysis we excluded non-Caucasian patients;

\section{Controls}

We had two control series available for analysis. Series (1) comprised spouses of patients enrolled in an UK population based study of colorectal cancer (number available $=285 ; 136$ female, 149 male; number informative $=276$ ). Of these informative controls, 142 were male and 134 were female. Series (2) was selected from the controls in an UK population based study of breast cancer diagnosed $\leqslant 45$ years age (number available $=223$, number informative=193;). The controls in series (2) were female. All controls were cancer free at the time of ascertainment. A total of 469 control samples were genotyped.

\section{DNA extraction}

DNA was extracted from blood samples by routine methods with the inclusion of a second proteinase $\mathrm{K}$ digestion at $50^{\circ} \mathrm{C}$. (Edwards et al, 1997). DNA was dissolved in 0.2 to $0.4 \mathrm{ml}$ of water $(\mathrm{BDH}$, Poole, UK) and stored at $-20^{\circ} \mathrm{C}$ until required.

\section{PCR and genotyping}

Ser217Leu variant The PCR primers used were designed by Tavtigian et al (2001) and also published by Rebbeck et al (2000). The region containing the Ser217Leu variant was amplified as described by Rebbeck et al (2000) using a $65^{\circ}-51^{\circ} \mathrm{C}$ touchdown protocol. The $335 \mathrm{bp}$ PCR product $(15 \mu \mathrm{l})$ was digested overnight with $15 \mathrm{U}$ Taq I $\alpha$ (NEB RO149L) at $65^{\circ} \mathrm{C}$. Genotypes were visualised on a $2.5 \%$ Agarose Gel (Metaphor Agarose). The PCR product sizes after digestion were either $173+162 \mathrm{bp}$, for the Ser/ Ser genotype or $335 \mathrm{bp}$ for the uncut Leu/Leu genotype or $335+173+162$ bp for the Ser/Leu genotype.

Ala541Thr variant The primers used to amplify the region of the Ala541Thr variant were described by Rebbeck et al (2000). The PCR product was digested overnight with $2 \mathrm{U}$ Fnu4HI (NEB, R0178L) at $37^{\circ} \mathrm{C}$. The digested $495 \mathrm{bp}$ PCR product was visualised as either $250+110 \mathrm{bp}$ fragment (Ala/Ala genotype) or as $250+162+110 \mathrm{bp}(\mathrm{Ala} / \mathrm{Thr}$ genotype) always with three smaller fragments $(34,49,52 \mathrm{bp})$. We did not observe any Thr/Thr genotypes $(250+162+49+34 \mathrm{bp})$.

\section{Analysis}

Analyses of genotype frequencies for each polymorphism were based on all cases and controls successfully typed for each polymorphisms, whereas analyses of combined genotypes at codons 217 and 541 were based on individuals successfully genotyped at both loci (Table 2), so the numbers of cases and controls differ slightly between analyses. Differences in genotype frequencies between cases and controls were tested using standard chi-squared tests. Odds ratios and confidence limits were calculated using standard methods. Trends in genotype frequencies by age at diagnosis were tested using logistic regression. The meta-analysis of genotypic risks over all studies was also conducted using logistic regression, treating each study as a separate stratum.

\section{RESULTS}

The estimated allele frequencies in the combined control series were $2.4 \%$ for the Thr541 allele and $28.3 \%$ for the Leu 217 allele (based on 457 controls, successfully genotyped for both polymorphisms). In agreement with previous studies we observed a Thr541 allele only in the presence of a Leu217 allele. The control frequency of the Leu217 allele (32 vs 26\%) and of the Thr541 allele (3.4 vs $1.6 \%$ ) was higher in series (2) than in series (1) controls. Neither difference was, however, statistically significant $\left(\chi^{2}=2.28\right.$, $P=0.13$ and $\left.\chi^{2}=3.51, P=0.06\right)$ respectively and we therefore combined our control series for the main analysis. There was also

Table I All Ala54I homozygotes compared to individuals who carried the Thr54I allele

\begin{tabular}{|c|c|c|c|c|c|c|c|}
\hline \multirow[b]{2}{*}{ Ser2 I7Leu genotype } & \multirow[b]{2}{*}{ Ala54IThr genotype } & \multirow{2}{*}{$\begin{array}{l}\text { Controls } \\
\text { No. (\%) }\end{array}$} & \multicolumn{2}{|c|}{ Cases $\leqslant 55$ years } & \multicolumn{2}{|c|}{ Cases $>55$ years } & \multirow{2}{*}{$\begin{array}{c}\text { All cases } \\
\text { OR (Cl 95\%) }\end{array}$} \\
\hline & & & No. (\%) & OR (Cl 95\%) & No. (\%) & OR (Cl 95\%) & \\
\hline Any & A/A & 447 (95\%) & $244(93 \%)$ & 1.00 & $160(94 \%)$ & 1.00 & 1.00 \\
\hline Any & Any $T$ & $22(5 \%)$ & $18(7 \%)$ & $1.50(0.79-2.85)$ & $10(6 \%)$ & $1.27(0.59-2.74)$ & $1.41(0.79-2.50)$ \\
\hline
\end{tabular}

Table 2 Case-control comparison of HPC2/ELAC2 genotypes

\begin{tabular}{|c|c|c|c|c|c|c|c|}
\hline Ser2I7Leu genotype & Ala54IThr genotype & $\begin{array}{l}\text { Controls } \\
\text { No. (\%) }\end{array}$ & \multicolumn{2}{|c|}{ Cases $\leqslant 55$ years } & \multicolumn{2}{|c|}{ Cases $>55$ years } & $\begin{array}{c}\text { All cases } \\
\text { OR (Cl 95\%) }\end{array}$ \\
\hline $\mathrm{S} / \mathrm{S}$ & $\mathrm{A} / \mathrm{A}$ & 242 (53\%) & $112(46 \%)$ & 1.00 & 86 (52\%) & 1.00 & 1.00 \\
\hline $\mathrm{L} / \mathrm{L}$ & $\mathrm{A} / \mathrm{A}$ & 38 (8\%) & $17(7 \%)$ & $0.97(0.52-1.79)$ & $18(11 \%)$ & $1.33(0.72-2.45)$ & $1.13(0.69-1.86)$ \\
\hline Any & Any $T$ & $22(5 \%)$ & $18(7 \%)$ & $1.77(0.91-3.43)$ & $10(6 \%)$ & $1.27(0.58-2.79)$ & $1.56(0.87-2.81)$ \\
\hline
\end{tabular}

'Any' describes either the genotype $S / L$ or $L / L$ (in Ser2 I l Leu column) - S/S was not observed together with the A54IT variant; 'Any T' describes the genotype A/T, as no homozygous Thr54I genotypes were observed. 
Table 3 Meta analysis comparing results of the seven published association studies (A54IT) together with the current study

\begin{tabular}{|c|c|c|c|c|c|}
\hline Study & \multicolumn{2}{|c|}{ Cases [n] } & \multicolumn{2}{|c|}{ Controls [n] } & OR $(95 \% \mathrm{Cl})$ \\
\hline Tavtigian et al, 200 $1^{\mathrm{a}}$ & 387 & 42 & 143 & 5 & $3.10(1.20-8.00)$ \\
\hline Vesprini et al, 200। & 404 & 27 & 1408 & 97 & $0.97(0.62-\mid .51)$ \\
\hline Suarez et al, 200। & 232 & 25 & 342 & 13 & $2.83(1.42-5.66)$ \\
\hline Rökman et al, 200I & 531 & 43 & 526 & 42 & $1.01(0.65-1.58)$ \\
\hline Wang et al, 200। & 399 & 46 & 450 & 52 & $1.00(0.66-1.52)$ \\
\hline Combined & 3011 & 271 & 3731 & 256 & $1.27(1.06-1.54)$ \\
\hline
\end{tabular}

${ }^{a}$ Comparison with 'divergent controls' (married-in spouses from other cancer families). ${ }^{b}$ Xu et al (200I) present an age-adjusted OR of I.09 (95\% Cl 0.58-2.05). For consistency with the other studies, the unadjusted OR (which is almost identical) is presented here.

no significant difference between the allele frequencies of males and females within control series (1).

To do the main calculations for the association between the Thr541 variant and PrCa risk, another $18 \mathrm{PrCa}$ cases diagnosed $\leqslant 55$ years and also four PrCa cases diagnosed $>55$ years, that only failed for the Ser217Leu genotype were included in the analyses. We found no significant difference in the frequency of Thr541 containing genotypes between cases and controls (OR $1.41,95 \%$ CI $0.79-2.50$, Table 1). This remained true when attention was restricted to patients diagnosed $\leqslant 55$ years (OR $1.50,95 \%$ CI $0.79-2.85$ ) or to patients diagnosed at $>55$ years (OR 1.27, 95\% CI $0.59-2.74)$. There were also no significant differences in the genotype frequencies of the Ser217Leu polymorphism. Estimated odds ratio for the genotypes based on both polymorphisms (Leu217/Thr541 genotypes; S/L/A/T, L/L/A/T) are shown in Table 2. The odds ratio for Thr541 carriers, compared with Ser217/Ala541 homozygotes was slightly elevated (1.56, 95\% CI $0.87-2.81$ ) but still not significantly different from 1.00 . We also tested for a trend in Thr541 frequency with age at diagnosis, but found no significant effect.

\section{DISCUSSION}

We attempted to replicate the association between Thr541 and PrCa risk reported by Tavtigian et al (2001) and Rebbeck et al (2000), but found no significant effect in our dataset. The estimated effect in our study (odds ratio 1.41) was in the same direction as the previous studies, but the magnitude of the effect was markedly smaller. However confidence limits on these odds ratios are still wide, and the results are still consistent with a two-fold increased risk.

We also analysed the data on the basis of combined Ser217Leu and Ala541Thr genotypes. We found a slightly higher odds ratio for Thr541 carriers compared with Ser217/Ala541 homozygotes (OR 1.56, 95\% CI 0.87-2.81; Table 2) and compared with all other Ala541 homozygotes (OR 1.41, 95\% CI 0.79-2.50, Table 1). This difference is a result of the slightly (but not significantly) higher frequency of Ser217/Leu217 carriers in PrCa cases, a trend which is more marked in cases diagnosed $\leqslant 55$ years $(\mathrm{OR}=1.35$, 95\% CI $0.96-1.89)$. This effect was also seen by Tavtigian et al (2001) and Rebbeck et al (2000). If these were true differences, they would imply a small PrCa risk associated with the Leu substitution and a larger risk associated with Thr541. However, the Leu217 effect is not significant in any study.

A notable feature of our study was the large proportion of cases $(n=262)$ diagnosed at $\leqslant 55$ years of age, which we ascertained through an UK national study of early onset PrCa. The familial risk of $\mathrm{PrCa}$ is much higher at young ages (Carter et $a l, 1992)$ and one might therefore expect any effect of HPC2 to be stronger in this age group. Moreover, screen detected disease is almost entirely absent in this group. The estimated odds ratio associated with Thr541 was higher in this age group, but it was still less than two and not significantly different from that in the older age group (OR 1.77, 95\% CI $0.91-3.43$ vs $1.27,95 \%$ CI $0.58-2.79$ ).

Suarez et al (2001) did not find a significant difference in the frequency of Ser217Leu variants between cases and controls $\left(\chi^{2}=1.79 ; P=0.18\right)$ but found a significantly greater frequency of the Ala541Thr variant in cases than in controls $\left(\chi^{2}=7.13\right.$; $P=0.008)$; this gives an estimated OR of 3.6 (95\% CI $1.8-7.3)$. The study genotyped $257 \mathrm{PrCa}$ patients (multiplex sibships) and 355 race matched healthy unrelated controls. No excess clustering of the Thr541 allele was found within the multiplex families which suggested no evidence for linkage of $\mathrm{PrCa}$ to the HPC2/ELAC2 gene.

Four other recent studies showed a negative risk association of HPC2 with PrCa. Xu et al (2001) exclude a major contribution of HPC2/ELAC2 as a high-prevalence, high-penetrance major gene for $\mathrm{PrCa}$ after performing linkage analysis in multiple case $\mathrm{PrCa}$ families and mutation screening (using DHPLC) of all coding exons of the gene in 93 probands. The study also genotyped 159 PrCa probands with a family history (hereditary prostate cancer, HPC), 249 PrCa patients with sporadic PrCa and 211 unaffected male control subjects. The results for Thr541 carrier frequencies were $10.5 \%$ for HPC patients, $9.0 \%$ for patients with sporadic PrCa and $9.0 \%$ for the control subjects. (HPC OR=1.37, 95\% CI $0.61-$ 3.11 for low risk allele S/S/A/A)

In another recently published study by Vesprini et al (2001), 431 screen detected $\mathrm{PrCa}$ patients with an elevated serum-PSA level $\left(>4.0 \mathrm{ng} \mathrm{ml}^{-1}\right.$ ) were genotyped for the two missense mutations Ser217Leu and Ala541Thr. Also $531 \mathrm{men}$, who underwent prostatic biopsy but had no evidence of invasive cancer were genotyped and were then used as male controls. Another control population consisted of 922 healthy, unselected women from the same population. The group found a similar Thr541allele frequency between 6.3 and $6.8 \%$ for all their patients and controls respectively, which lead to the conclusion that the Thr541 variant is unsuitable for use as a screening method for PrCa patients with a raised PSA. There was no association between the Ala541Thr variant and the risk of screen detected PrCa (OR 1.10; 95\% CI 0.48-2.50; $P=0.84$ ).

Rökman et al (2001) genotyped 107 HPC cases, 467 unselected $\mathrm{PrCa}$ cases and 223 benign prostatic hyperplasia (BPH) cases and 568 healthy male blood donors for the two HPC2 variants Leu217 and Thr541. The study found no difference in the frequencies of Leu217 and Thr541 in HPC patients, unselected PrCa patients or the control group $(42-54 \%$ and $7.5 \%)$ respectively, but a slightly higher frequency of the Thr 541 variant was observed in the $\mathrm{BPH}$ cases $(\mathrm{OR}=1.73,95 \% \mathrm{CI} 1.04-2.87)$. The group also 
performed mutation screening in the HPC2/ELAC2 gene using SSCP and found the variant Glu622Val. The results showed an almost three-fold increased risk of PrCa in carriers of the Val622 mutation compared to non-carriers $(\mathrm{OR}=2.94,95 \% \mathrm{CI} 1.05-8.23)$.

Wang et al (2001) found no association of Ser217Leu and Ala541Thr with PrCa risk by genotyping $446 \mathrm{PrCa}$ patients from 164 families and 502 population based controls (OR=1.04; 95\% CI $0.57-1.89)$. The Leu217 frequency in $\mathrm{PrCa}$ patients was $32.3 \%$ and in controls $31.8 \%$. The frequency of the Thr541 variant was $5.4 \%$ in patients $v s 5.2 \%$ in controls.

In order to evaluate the overall evidence for an effect of the Ala541Thr polymorphism on PrCa risk, we performed a metaanalysis based on the results of the seven published studies (Rebbeck et al, 2000; Rökman et al, 2001; Suarez et al, 2001; Tavtigian et al, 2001; Vesprini et al, 2001; Wang et al, 2001; Xu et al, 2001), together with the current study (Table 3). The estimated odds ratio for the Thr541 carriers compared with all other genotypes was $1.27(95 \%$ CI $1.06-1.54, P=0.012)$. However, there is significant evidence of heterogeneity in the odds ratio estimates among the studies $\left(\chi_{2}{ }^{7}=16.18, P=0.024\right)$. If the Vesprini et al (2001) data (which is based on screen detected cancers and

\section{REFERENCES}

Carter BS, Beaty TH, Steinberg GD, Childs B, Walsh PC (1992) Mendelian inheritance of familial prostate cancer. Proc Natl Acad Sci USA 89: $3367-3371$

Eeles RA, the UK Familial Prostate Study Co-ordinating Group, the CRC/ BPG UK Familial Prostate Cancer Study Collaborators (1999) Genetic predisposition to prostate cancer. Prostate Cancer and Prostatic Diseases 2: $9-15$

Edwards SM, Dearnaley DP, Ardern-Jones A, Hamoudi RA, Easton DF, Ford D, Shearer R, Dowe A, Eeles RA (1997) No germline mutations in the dimerization domain of MXI1 in prostate cancer clusters. The CRC/BPG UK Familial Prostate Cancer Study Collaborators. Cancer Research Campaign/British Prostate Group. Br J Cancer 76(8): $992-1000$

Rebbeck TR, Walker AH, Zeigler-Johnson C, Weisburg S, Martin AM, Nathanson KL, Wein AJ, Malkowicz SB (2000) Association of HPC2/ ELAC2 genotypes and prostate cancer. Am J Hum Genet 67: 1014-1019

Rökman A, Ikonen T, Mononen N, Autio V, Matikainen MP, Koivisto PA Tammela TLJ, Kallioniemi OP, Schleutker J (2001) ELAC2/HPC2 involvement in hereditary and sporadic prostate cancer. Cancer Res 61: 60386041

Suarez BK, Gerhard DS, Lin J, Haberer B, Nguyen L, Kesterson NK, Catalona WJ (2001) Polymorphisms in the prostate cancer susceptibility gene HPC2/ELAC2 in multiplex families and healthy controls. Cancer Res 61(13): $4982-4984$ controls undergoing screening) is excluded, the estimated odds ratio was 1.36 ( $95 \%$ CI $1.10-1.68, P=0.004)$. However, if the initial hypothesis-generating studies of Tavtigian et al (2001) and Rebbeck et al (2000) are also excluded, the evidence is much weaker (OR $1.21,95 \%$ CI $0.96-1.53, P=0.10)$.

We conclude that the HPC2 variants are associated with, at most, a moderate increased risk of PrCa. In particular Thr541 is unlikely to be associated with a risk of more than 1.5 -fold.

\section{ACKNOWLEDGEMENTS}

We thank Sheila Seal and Anita Hall for kindly storing and databasing the samples. The authors also thank Sean Tavtigian for providing the primer sequences and for helpful discussions. We thank the patients who participated in this study. Funds were generously provided by The Prostate Cancer Charitable Trust and Cancer Research UK (formerly Cancer Research Campaign, grant no. SP2304/0201 - Translational research in individuals with genetic predisposition to cancer).

Tavtigian SV, Simard J, Teng DH, Abtin V, Baumgard M, Beck A, Camp NJ, Carillo AR, Chen Y, Dayananth P, Desrochers M, Dumont M, Farnham JM, Frank D, Frye C, Ghaffari S, Gupte JS, Hu R, Iliev D, Janecki T, Kort EN, Laity KE, Leavitt A, Leblanc G, McArthur-Morrison J, Pederson A, Penn B, Peterson KT, Reid JE, Richards S, Schroeder M, Smith R, Snyder SC, Swedlund B, Swensen J, Thomas A, Tranchant M, Woodland AM, Labrie F, Skolnick MH, Neuhausen S, Rommens J, Cannon-Albright LA (2001) A candidate prostate cancer susceptibility gene at chromosome 17p. Nat Genet 27(2): $172-180$

Vesprini D, Nam RK, Trachtenberg J, Jewett MA, Tavtigian SV, Emami M, Ho M, Toi A, Narod SA (2001) HPC2 variants and screen-detected prostate cancer. Am J Hum Genet 68(4): 912-917

Wang L, McDonnell SK, Elkins DA, Slager SL, Christensen E, Marks AF, Cunningham JM, Peterson BJ, Jacobsen SJ, Cerhan JR, Blute ML, Schaid DJ, Thibodeau SN (2001) Role of HPC2/ELAC2 in hereditary prostate cancer. Cancer Res 61(17): 6494-6499

Xu J, Zheng SL, Carpten JD, Nupponen NN, Robbins CM, Mestre J, Moses TY, Faith DA, Kelly BD, Isaacs SD, Wiley KE, Ewing CM, Bujnovszky P, Chang B, Bailey-Wilson J, Bleecker ER, Walsh PC, Trent JM, Meyers DA, Isaacs WB (2001) Evaluation of linkage and association of HPC2/ ELAC2 in patients with familial or sporadic prostate cancer. Am J Hum Genet 68(4): $901-911$ 